\title{
PENGARUH COST OF BORROWING, PROFITABILITY DAN COLLATERAL VALUE OF ASSETS TERHADAP STRUKTUR MODAL PADA PERUSAHAAN REAL ESTATE DI INDONESIA
}

\author{
Ade Suryana \\ Institut Ilmu Sosial dan Manajemen STIAMI \\ adesuryana@yahoo.com
}

\begin{abstract}
Abstrak. Genarlli, tujuan utama sebuah perusahaan adalah memaksimalkan kekayaan pemegang sahamnya. Bagi perusahaan publik, itu berarti memaksimalkan kembali sahamnya yang beredar. Keputusan akhir yang dibuat oleh manajemen, yang terdiri dari keputusan investasi dan keputusan pembiayaan. Industri real estat adalah industri padat modal yang menghabiskan dana besar untuk memulai operasinya. Akibatnya, sebagian besar perusahaan real estat akan mencari dan mengandalkan pinjaman dari pihak ketiga sebagai sumber pembiayaan utamanya selain modalnya sendiri.

Tujuan dari penelitian ini adalah untuk mengetahui apakah ada pengaruh biaya pinjaman, profitabilitas, dan nilai agunan atas aktiva pada struktur modal.

Hipotesis untuk penelitian ini adalah: (a) untuk mengetahui apakah ada pengaruh biaya pinjaman terhadap struktur modal pada perusahaan real estat di Indonesia, (b) untuk mengetahui apakah ada pengaruh profitabilitas terhadap struktur modal pada perusahaan real estat di Indonesia , (c) untuk mengungkapkan apakah ada pengaruh nilai agunan aset pada struktur modal pada perusahaan real estat di Indonesia, dan (d) untuk mengetahui apakah ada pengaruh biaya pinjaman, profitabilitas dan nilai agunan atas aset, pada saat bersamaan, pada struktur modal di perusahaan real estat di Indonesia.

Dengan menggunakan regresi linier berganda untuk menguji hipotesis tersebut, data yang diperoleh dari perusahaan real estat yang terdaftar di Bursa Efek Indonesia selama tahun 2003-2007 mengungkapkan bahwa: (a) ada pengaruh negatif dan signifikan biaya pinjaman terhadap struktur modal pada perusahaan real estat di Indonesia , (b) ada pengaruh positif dan signifikan terhadap profitabilitas struktur modal pada perusahaan real estat di Indonesia, (c) terdapat pengaruh positif dan signifikan nilai agunan aset pada struktur modal pada perusahaan real estat di Indonesia, dan (d) ada pengaruh yang signifikan dari biaya pinjaman, profitabilitas dan nilai agunan aset, secara simultan, terhadap struktur modal pada perusahaan real estat di Indonesia.

Hasil penelitian menunjukkan bahwa biaya pinjaman merupakan faktor yang secara signifikan menentukan struktur modal. Mendapatkan pinjaman dari pihak ketiga akan menghasilkan kenaikan biaya bunga, dan pada gilirannya menghasilkan laba bersih yang rendah, dibandingkan dengan perusahaan yang menggunakan sumber pembiayaan mereka sendiri. Tentu saja, keputusan untuk membiayai perusahaan melalui fasilitas pinjaman harus didasarkan pada analisis dan perhitungan mendalam terutama terkait kemampuan perusahaan untuk penyelesaian.
\end{abstract}

Kata kunci: Biaya pinjaman, Profitabilitas dan nilai agunan aset

Abstract. Genarlli, the main goal of a company is to maximize its shareholders' wealth. For a public company, it means maximizing return to its outstanding shares. The final decisions made by the management, which comprise of investment decision and financing decision. Real estate industry is a capital-intensive industry that would spend large fund to start the operations. Consequently, most real estate companies would search and rely upon loan from third parties as its main financing source other than its own capital.

The objective of this research is to reveal whether there is influence of cost of borrowing, profitability, and collateral value of assets on capital structure. 
Th hypothesis for this research are: (a) to reveal whether there is influence of cost of borrowing on capital structure in real estate companies in Indonesia, (b) to reveal whether there is influence of profitability on capital structure in real estate companies in Indonesia, (c) to reveal whether there is influence of collateral value of assets on capital structure in real estate companies in Indonesia, and $(d)$ to reveal whether there is influence of cost of borrowing, profitability and collateral value of assets, simultaneously, on capital structure in real estate companies in Indonesia.

Using multiple linear regressions to test those hypotheses, the data obtained from real estate companies listed in Indonesia Stock Exchange during 2003-2007 revealed that: (a) there is negative and significant influence of cost of borrowing on capital structure in real estate companies in Indonesia, $(b)$ there is positive and significant influence of profitability on capital structure in real estate companies in Indonesia, (c) there is positive and significant influence of collateral value of assets on capital structure in real estate companies in Indonesia, and (d) there is significant influence of cost of borrowing, profitability and collateral value of assets, simultaneously, on capital structure in real estate companies in Indonesia.

The result of this research indicated that cost of borrowing is the factor that significantly determines the capital structure. Obtaining loan from third parties would result higher interest expenses, and in turn result in low net income, compared to companies that use their own source of financing. Of course, the decision to finance a company through loan facilities should be based on in-depth analysis and calculation especially in relation to the company's capability for settlement.

Key Word : Cost of borrowing, Profitability and collateral value of assets

\section{PENDAHULUAN}

Krisis keuangan dunia yang melanda pada kuartal IV tahun 2008 menyebabkan laju pertumbuhan ekonomi yang mengalami penurunan. Kondisi tersebut menyebabkan banyak perusahaan yang sulit untuk bertahan. Dalam situasi seperti ini diperlukan keputusan yang tepat oleh manajemen agar perusahaan bisa bertahan dan terus berkembang. Salah satu keputusan yang diperlukan adalah penetapan struktur modal (capital structure) perusahaan.

Struktur modal merupakan kombinasi dari berbagai jenis sumber dana yang digunakan perusahaan yang terdiri dari hutang jangka panjang dan modal sendiri yang berupa saham preferen, saham biasa dan laba ditahan.

Keputusan pendanaan di suatu perusahaan merupakan aspek yang sangat penting dalam mempelajari strategi keuangan perusahaan. Pendanaan perusahaan bisa berasal dari hutang (debt) atau dari ekuitas (equity). Perusahaan bisa menggunakan berbagai alat pendanaan dengan teknik kombinasi yang berbeda-beda sesuai dengan kondisi internal dan eksternal dalam rangka mendapatkan kombinasi yang paling optimal untuk bertahan atau bahkan memperluas bisnisnya. Kombinasi struktur pendanaan sering disebut debt to equity ratio atau leverage ratio yang merupakan rasio hutang perusahaan terhadap ekuitasnya.

Dalam menentukan kombinasi antara hutang dan modal, perusahaan akan mempertimbangkan faktor-faktor yang akan mempengaruhinya. Bhole dan Mahakud (2004) menyebutkan bahwa struktur modal perusahaan dipengaruhi oleh cost of borrowing, cost of equity, size of the firm, profitability, growth rate, collateral of assets, liquidity dan non-debt tax shields.

Perusahaan dapat menggunakan lebih banyak hutang karena biaya hutang atau biaya bunganya lebih murah jika dibandingkan dengan menggunakan modal sendiri. Dalam hal ini biaya modal lebih mahal karena perusahaan harus mengeluarkan biaya untuk membayar deviden kepada pemegang sahamnya atas kepemilikan saham di perusahaan.

Selain faktor besar kecilnya biaya hutang atau modal sendiri yang digunakan terdapat beberapa faktor lain yang mempengaruhi struktur modal oleh perusahaan. Riset empiris terhadap struktur 
modal telah dilakukan pada penelitian sebelumnya yang menganalisa faktor-faktor yang menentukan struktur modal pada perusahaan di Polandia dan Hongaria (Alexander Devic, Bojan Ristc, 2001), dimana menurut riset ini, faktor penting penentu sruktur modal pada perusahaan adalah ukuran perusahaan tersebut (size), proporsi aktiva tetap dari total assets (tangibility), profitabilitas (profitability), dan peluang pertumbuhan (growt opportunity).

Dari segi profitabilitas, perusahaan yang memiliki tingkat profitabilitas tinggi akan memiliki kekuatan dalam hal pendanaan. Sebaliknya perusahan yang tingkat profitabilitasnya kecil cenderung tidak memiliki kekuatan dalam hal pendanaan.

Menurut Donaldson dalam Booth et al (2001) tingkat keuntungan perusahaan (profitability) akan berpengaruh negative terhadap penggunaan hutang, yaitu semakin tingginya tingkat keuntungan yang diperoleh perusahaan dapat membiayai kegiatan usahanya dengan menggunakan laba yang diperoleh dalam bentuk laba ditahan (retained earning). Sebaliknya perusahaan dengan tingkat keuntungan rendah akan cenderung menggunakan hutang sebagai pembiayaannya.

Profitabilitas dari perusahaan dapat menggambarkan bagaimana citra sebuah perusahaan di mana calon investor yang hendak membeli saham perusahaan tersebut apabila terlihat dari laporan keuangan perusahaan tersebut menunjukkan atau terlihat selama ini saham perusahaan tersebut tidak memberikan profit yang signifikan maka calon investor akan mengurungkan niatnya. Profit dari sebuah perusahaan sangat berarti bagi beroperasinya sebuah perusahaan. Karena apabila perusahaan memiliki Return On Investment (ROI) besar, maka ketergantungan terhadap hutang menjadi sangat kecil. Hal inilah yang mendorong banyak perusahaan tetap meningkatkan profitabilitasnya mengingat apabila hanya bergantung pada hutang, maka perusahaan tidak akan mampu bertahan dan bersaing dengan perusahaan yang memiliki kemandirian besar.

Atas dasar itulah, maka penulis tertarik untuk meneliti bagaimana pengaruh cost of orrowing, profitability dan collateral value of assets terhadap struktur modal (capital structure) dari perusahaan-perusahaan real estate yang terdaftar di Bursa Efek Indonesia baik secara partial maupun simultan

\section{TINJAUAN PUSTAKA}

Konsep penting manajemen pendanaan adalah masalah sumber dan penggunaan dana. Dana dapat dipenuhi dari sumber internal maupun sumber eksternal perusahaan. Dana tersebut kemudian dipakai untuk membelanjai aktiva-aktiva perusahaan. Pada prinsipnya pemenuhan dan pengalokasian dana menyangkut masalah keseimbangan financial dala perusahaan. Yaitu mengadakan keseimbangan antara aktiva dan pasiva tersebut dengan sebaik-baiknya. Penyusunan kualitatif dari aktiva akan menentukan struktur kekakyaan, sednagkan pemilihan susunan kualitatif dari pasiva akan menentukan struktur keuangan (Bambang, 2001)

Struktur modal berkaitan dengan keputusan pendanaan yang dilakukan oleh perusahaan. Pengelola perusahaan harus berhati-hati dalam melakukan keputusan pendanaan karena akan memiliki implementasi pada menurunnya value perusahaan dan berarti menurunkan pendapatan para pemegang saham.

Pengertian struktur modal adalah bauran (proporsi) pendanaan permanen jangka panjang perusahaan yang ditunjukan oleh hutang, ekuitas saham preferen dan saham biasa. Struktur modal optimal adalah struktur modal yang meminimalkan biaya perusahaan dan memaksimalkan perusahaan (Van Horne, James C dan Wachowicz, Jr; 1998)

Menurut Bambang Riyanto (2001) pengertian struktur modal adalah pembelanjaan permanen dimana mencerminkan perimbangan antara hutang jangka panjang dengan modal sendiri, dimana kedua golongan tersebut merupakan dana permanen atau dana jangka panjang.

Struktur modal adalah perimbangan jumlah hutang jangka pendek yang bersifat permanent, hutang jangka panjang, saham preferen dan saham biasa. Sementara struktur keuangan adalah perimbangan antara total 
hutang dengan modal sendiri. Dengan kata lain struktur modal merupakan bagian dari struktur keuangan (Sartono, 2001;225).

Charles Schwab (2004) mendefinisikan struktur modal sebagai berikut :

Capital structure is the permanent long-term financing of a company, including long-term debt, common stock and preferred stoeck and retained earnings. It differs from financial structure, which includes short term debt and account payables.

Sartono (2001, p.257), dalam manajemen keuangan :

Leverage adalah penggunaan asset dan sumber dana (source of fund) oleh perusahaan yang memiliki biaya tetap (beban tetap) dengan maksud agar meningkatkan keuntungan potensial pemegang saham. Perusahaan menggunakan leverage dengan tujuan agar keuntungan yang diperoleh lebih besar daripada biaya asset dan sumber dananya, dengan demikian akan meningkatkan keuntungan pemegang saham. Sebaliknya leverage juga meningkatkan variabilitas (resiko) keuntungan, karena jika perusahaan ternyata mendapatkan keuntungan yang lebih rendah dari biaya tetapnya maka penggunaan leverage akan menurunkan keuntungan pemegang saham.

Tingkat biaya tetap aktiva dan dana yang dipilih oleh manajemen mempengaruhi variabilitas dari pengembalian, yaitu resiko yang dapat dikendalikan oleh manajemen. Karena pengaruhnya terhadap nilai, maka manajer keuangan harus memahami bagaimana mengukur dan mengevaluasi leverage, khususnya ketika membuat struktur modal yang optimal (Irawati, 2006). Ada tiga jenis leverage yaitu leverage operasi (operating leverage), leverage keuangan (financial leverage) dan leverage total/gabungan (combine leverage).

$$
\text { Leverage keuangan (financial }
$$
leverage) dapat diperoleh dari beberapa sumber. Salah satu sumber adalah hutang jangka panjang, seperti obligasi. Sumber dana lainnya adalah kewajiban jangka pendek atau saham preferen. Hutang jangka pendek selalu merupakan sumber positif bagi leverage, yaitu dana diperoleh untuk digunakan didalam perusahaan tanpa perlu biaya bunga dengan masuknya kreditor jangka pendek, sperti misalnya bila perusahaan membeli atau mendapatkan persediaan barang dari pemasok secara kredit, persediaan akan tersedia untuk digunakan tanpa memberikan biaya bunga kepada pemasok dengan jumlah hutang tersebut (Rahardjo; 2005).

\section{Struktur Modal}

Struktur modal suatu perusahaan memiliki beberapa komponen yang terdiri dari :

a. Hutang jangka panjang (long term debt): hutang dengan jangka waktu relative panjang, umumnya lebih dari 10 tahun, yang umumnya digunakan untuk membelanjai perluasan perusahaan (ekspansi) atau modernisasi perusahaan.

b. Saham preferen (preferred stock) : saham yang pemegang sahamnya memiliki preferensi tertentu di atas pemegang saham biasa terutama dalam hal pembagian deviden atau kekayaan.

c. Saham biasa (common stock) : saham yang pemegang sahamnya akan mendapatkan deviden pada akhir tahun jika perusahaan tersebut memperoleh keuntungan.

d. Laba ditahan (retained earning): yaitu keuntungan yang diperoleh perusahaan yang ditahan (tidak dibayarkan sebagai deviden) apabila kegunannya belum ditentukan oleh perusahaan.

\section{Teori Struktur Modal}

Menurut Penelitian Bhole dan Mahakud (2004), struktur keuangan perusahaan dapat ditunjukkan oleh beberapa rasio: (1) rasio pinjaman jangka panjang terhadap ekuitas (long-term borrowing to equity), (2) total pinjaman (jangka pendek dan jangka panjang) terhadap ekuitas (total borrowing to liabilities), (3) total pinjaman terhadap total kewajiban (total borrowing to total liabilities), dan (4) pinjaman jangka panjang terhadap pinjaman jangka pendek (long term borrowing to short term borrowing). 
Ade Suryana, Pengaruh Cost Of Borrowing, Profitability Dan Collateral Value Of Assets...

\section{Cost of Borrowing (CB)}

Cost of borrowing (CB) merupakan faktor yang perlu dipertimbangkan dalam menganalisis kebijakan leverage. Melalui faktor ini, bukan hanya suku bunga actual pinjaman yang dapat dianalisa, tetapi juga meliputi total biaya yang dikeluarkan perusahaan untuk hutang yang diambilnya, yang merupakan biaya tetap bagi perusahaan. Cost of borrowing merupakan rasio antara jumlah bunga pinjaman yang dibayar dibandingkan dengan jumlah hutang itu sendiri.

\section{Profitability (PR)}

Profitability (PR) merupakan rasio antara operating income terhadap total asset. Perusahaan dengan rate of return yang tinggi mempunyai kecenderungan menggunakan proporsi hutang yang relative kecil karena kebutuhan dana yang dapat diperoleh dari laba ditahan. Hal ini konsisten dengan penelitian Myers yang menyarankan agar manajer menggunakan laba ditahan (retained earning) dijadikan pilihan utama, diikuti debt financing baru kemudian equity untuk memenuhi kebutuhan keuangan perusahaan.
Maka diasosiasikan ada hubungan negative dan signifikan antara profitabilitas terhadap struktur modal.

\section{Colleteral Value of Assets (CVA)}

Collateral value of assets (CVA) merupakan rasio antara piutang usaha ditambah jumlah assets bersih dibandingkan dengan total asset. Tangibility menurut Jensen dan Meckling (dalam sartono, 2001) yaitu harta yang berwujud memberikan jaminan uang lebih baik untuk pinjaman dana juga leverage yang besar.

Collateral value of assets (CVA) memiliki hubungan yang positif dengan jumlah pemakaian hutang. Ratio fixed asset to total assets (FTA) merupakan proxy dari collateral value of assets, fixed asset seringkali digunakan sebagai jaminan dalam mendapatkan hutang yang lebih banyak dibandingkan perusahaan yang memiliki keadaan sebaliknya.

\section{Kerangka Pemikiran}

Berdasarkan uraian di atas, dapat dibuat bagan kerangka pemikiran sebagai berikut:

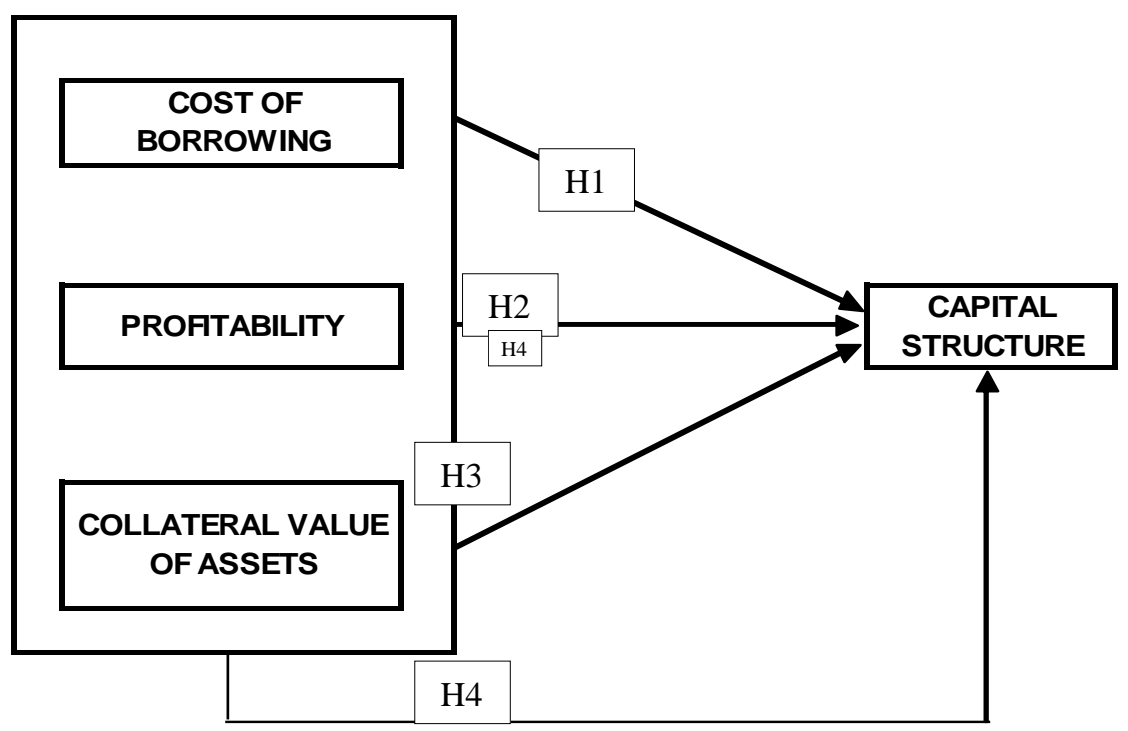

Gambar 1. Kerangka Pemikiran

\section{Perumusan Hipotesis}

Berdasarkan permasalahan dan tujuan penelitian, maka disusun 4 hipotesis sebagai berikut:

$\mathrm{H}_{\mathrm{a}} 1$ : Terdapat pengaruh negatif cost of borrowing terhadap struktur modal.
$\mathrm{H}_{\mathrm{a}}$ 2: Terdapat pengaruh negatif profitability terhadap struktur modal.

$\mathrm{H}_{\mathrm{a}} 3$ : Terdapat pengaruh positif collateral value of assets terhadap struktur modal.

$\mathrm{H}_{\mathrm{a}} 4$ : Terdapat pengaruh positif cost of borrowing, profitability dan collateral 
value of assets secara simultan terhadap struktur modal.

\section{METODOLOGI}

\section{Operasional Variabel}

Dalam penelitian ini variabel tidak bebas "Independent variable" yang ditetapkan adalah struktur modal (capital structure). Sedangkan variabel bebas "dependent variable" adalah cost of borrowing, profitability dan collateral value of assets. Penjelasan mengenai variabel-variabel di atas beserta indikatornya dapat dilihat dalam tabel 1 berikut ini:

Tabel 1

Variabel dan Pengukurannya

\begin{tabular}{|c|c|c|}
\hline Variabel & Indikator & Skala Pengukuran \\
\hline \multicolumn{3}{|l|}{ Variabel Bebas } \\
\hline \multirow{2}{*}{$\begin{array}{l}\text { Biaya pinjaman } \\
\text { (cost of borrowing) }\end{array}$} & Total Bunga Pinjaman & \multirow[t]{2}{*}{ Rasio } \\
\hline & $\overline{\text { Total Pinjaman }}$ & \\
\hline \multirow{2}{*}{$\begin{array}{l}\text { Tingkat } \quad \text { Keuntungan } \\
\text { (Profitability) }\end{array}$} & Total Laba Operasi & \multirow[t]{2}{*}{ Rasio } \\
\hline & Total Asset & \\
\hline \multirow[t]{2}{*}{$\begin{array}{l}\text { Nilai Jaminan Asset } \\
\text { (collateral value of assets) }\end{array}$} & $\begin{array}{l}\text { Total Piutang+Persediaan } \\
+ \text { Aktiva bersih } \\
\end{array}$ & \multirow[t]{2}{*}{ Rasio } \\
\hline & Total Asset & \\
\hline \multicolumn{3}{|l|}{ Variabel Terikat } \\
\hline \multirow{2}{*}{$\begin{array}{l}\text { Struktur Modal } \\
\text { (Capital structure) }\end{array}$} & Total Pinjaman & \multirow[t]{2}{*}{ Rasio } \\
\hline & Total Ekuitas & \\
\hline
\end{tabular}

Sumber: Bhole dan Mahakud (2004)

Pada penelitian ini, variabel bebas dan terikat yang akan dianalisis dilambangkan sebagai berikut :

$\mathrm{CB}$ : $\begin{gathered}\text { Biaya bunga pinjaman (cost of } \\ \text { borrowing) }\end{gathered}$

PR : Tingkat keuntungan (profitability)

CVA: Nilai jaminan assets (collateral value of asets)

CS : Sruktur modal (capital structure)

Definisi atas variabel-variabel tersebut adalah:

\section{Cost of borrowing (CB)}

Cost of borrowing dapat diukur sebagai persentase jumlah biaya bunga pinjaman untuk total keseluruhan pinjaman perusahaan. Diperkirakan cost of borrowing memiliki pengaruh negative terhadap struktur modal (capital structure)

\section{Profitability (PR)}

Profitability merupakan persentase laba operasi terhadap total assets yang dimiliki oleh perusahaan. Diperkirakan profitability memiliki pengaruh negative terhadap struktur modal.

\section{Collateral value of assets (CVA)}

Collateral value of assets merupakan rasio dari total piutang ditambah persediaan dan aktiva tetap bersih terhadap total assets yang dimiliki oleh perusahaan. Diperkirakan collateral value of assets memiliki pengaruh positif terhadap sruktur modal.

\section{Capital Structure (CS)}

Struktur modal (capital structure) merupakan rasio dari total pinjaman baik jangka pendek dan jangka panjang yang bersifat permanen terhadap total ekuitas yang dimiliki oleh perusahaan.

\section{Pemilihan Metode Penelitian}


Ade Suryana, Pengaruh Cost Of Borrowing, Profitability Dan Collateral Value Of Assets...

Metodologi penelitian yang digunakan adalah uji hipotesis dengan menggunakan analisis multiple linear regression untuk menguji pengaruh cost of borrowing, profitability dan collateral value of assets terhadap struktur modal pada perusahaan real estate yang listed di Bursa Efek Indonesia baik secara partial maupun simultan.

\section{Populasi dan Sampel}

Populasi obyek penelitian ini adalah perusahaan publik yang bergerak di sektor real estate dan terdaftar di Bursa Efek Jakarta. Waktu pengamatan untuk penelitian ini adalah 5 tahun, dari tahun 2003 sampai tahun 2007.

\section{Deskripsi dan Karakteristik Objek Penelitian}

Perusahaan-perusahaan real estate yang dijadikan sampel dalam penelitian ini dapat dilihat sebagai berikut:

\section{Tabel 2}

Emiten Real Estate di Bursa Efek Indonesia

\begin{tabular}{|c|l|}
\hline No. & \multicolumn{1}{|c|}{ Jenis Usaha Real Estate } \\
\hline 1 & PT Suryamas Dutamakmur Tbk \\
\hline 2 & PT Royal Oak Development Asia Tbk \\
\hline 3 & PT Panca Wiratama Sakti Tbk \\
\hline 4 & PT Pudjiadi Prestige Tbk \\
\hline 5 & PT Indonesia Prima Property Tbk \\
\hline 6 & PT Lippo Cikarang Tbk \\
\hline 7 & PT Jaya Real Property Tbk \\
\hline 8 & PT Jakarta International Tbk \\
\hline 9 & PT Gowa Makassar Tourism Development Tbk. \\
\hline 10 & PT Duta Pertiwi Tbk. \\
\hline 11 & PT Dharmala Intiland Tbk. \\
\hline 12 & PT Summarecon Agung Tbk. \\
\hline 13 & PT Bukit Sentul Tbk. \\
\hline 14 & PT Pakuwon Jati Tbk. \\
\hline 15 & PT Modernland Realty Tbk. \\
\hline 16 & PT Ciputra Development Tbk \\
\hline 17 & PT Duta Anggada Realty Tbk. \\
\hline
\end{tabular}

Berikut adalah sekilas profil emiten-emiten tersebut:

a. PT Suryamas Dutamakmur Tbk.

Perusahaan didirikan pada 21 September 1989 bergerak di bidang real estate berupa penjualan tanah serta tanah dan rumah tinggal, pengoperasian lapangan golf, country club dan fasilitas resort lainnya di daerah Rancamaya, Bogor, Jawa Barat. Mulai efektif listing di bursa efek sejak 18 September 1995. Pada tahun 2007 perusahaan menderita rugi bersih Rp 11,7 milyar.

b. PT. Royal Oak Development Asia Tbk (d/h PT Roda Panggon Harapan Tbk.)

Perusahaan didirikan pada 15 Oktober 1984 bergerak di bidang pembangunan dan penjualan real estate Perumahan Simprug di Poris, tangerang. Mulai eketif listing di bursa efek sejak 28 September 2001. Pada tahun 2007 perusahaan menderita rugi bersih Rp 252 juta.

c. PT Panca Wiratama Sakti Tbk. 
Perusahaan didirikan pada 1 September 1986 bergerak di bidang real estate di Tangerang, Jawa Barat. Mulai eketif listing di bursa efek sejak 10 Februari 1994. Pada tahun 2007 perusahaan menderita rugi bersih $\mathrm{Rp}$ 45,3 milyar.

d. PT Pudjiadi Prestige Tbk

Perusahaan didirikan pada 11 September 1980 bergerak di bidang real estate, kontraktor dan penyewaan ruangan/apartemen. Mulai eketif listing di bursa efek sejak 28 September 1994. Pada tahun 2007 perusahaan memperoleh laba bersih Rp 6,8 milyar.

e. PT Indonesia Prima Property Tbk Perusahaan didirikan pada 23 April 1983 bergerak di bidang persewaan perkantoran, pusta perbelanjaan, apartemen, hotel dan perumahan. Mulai eketif listing di bursa efek sejak 29 Juni 1994. Pada tahun 2007 perusahaan mencatat laba bersih Rp 14,7 milyar.

f. PT Lippo Cikarang Tbk

Perusahaan didirikan pada tanggal 20 Juli 1987, bergrak dalam pengembangan kota (urban development) yang meliputi pengembangan kawasan perumahan dan industri, pembnagunan infrastruktur dan fasilitas umum, penyediaan jasa pendukung, serta melakukan investasi, baik secara langsung maupun tidak langsung melalui perusahaan anak maupun patungandengan pihak-pihak lain. Mulai listing di bursa efek sejak 27 Juni 1997. Pada tahun 2007 perusahaan mencatat laba bersih Rp 11,0 milyar.

g. PT Jaya Real Property Tbk.

Perusahaan didirikan pada 25 Mei 1979 bergerak di bidang pengembangan kota (urban development). Mulai efektif listing di bursa efek sejak 2 Juni 1994. Pada tahun 2007 perusahaan mencatat laba bersih Rp 110 juta.

h. PT Jakarta International Tbk

Perusahaan didirikan pada 7 November 1984 bergerak di bidang real estate, perhotelan, pusat perbelanjaan dan gedung perkantoran. Mulai efektif listing di bursa efek sejak 18 September 1995.
Pada tahun 2007 perusahaan mengalami kerugian Rp 219 juta.

i. PT Gowa Makassar Tourism Development Tbk.

Perusahaan didirikan pada tanggal 14 Mei 1991. Bergerak dalam bisang investasi dan pengembangan real estate dan properti. Mulai listing di bursa efek sejak tanggal 7 Desember 2000. Pada tahun 2007 perusahaan mencatat laba bersih Rp 11,0 milyar.

j. PT Duta Pertiwi Tbk.

Perusahaan didirikan pada 29 Desember 1972 bergerak di bidang real estate berupa pusat perbelanjaan. Mulai efektif listing di bursa efek sejak 26 September 1994. Pada tahun 2007 perusahaan mencatat laba bersih Rp 59 milyar.

k. PT Intiland Development Tbk. (d/h PT. Dharmala Intiland Tbk.)

Perusahaan didirikan pada 10 Juni 1983 bergerak di bidang real estate berupa pembangunan dan persewaa perkantoran. Mulai efektif listing di bursa efek sejak 21 Oktober 1989. Pada tahun 2007 perusahaan mencatat laba bersih $\mathrm{Rp} 26$ milyar.

1. PT Summarecon Agung Tbk.

Perusahaan didirikan pada 26 November 1975 bergerak di bidang pengembang real estate, penyewaan properti dan pengelolaan fasilitas rekreasi. Mulai efektif listing di bursa efek sejak 1 Maret 1990. Pada tahun 2007 perusahaan perusahaan mencatat laba bersih Rp 160 juta.

m. PT Bukit Sentul Tbk.

Perusahaan didirikan pada 8 Juni 1993 bergerak di bidang pengembang real estate, penyewaan properti dan pengelolaan fasilitas rekreasi. Mulai eketif listing di bursa efek sejak 30 Juni 1997. Pada tahun 2007 perusahaan mencatat laba bersih Rp 85,5 milyar.

n. PT Pakuwon Jati Tbk.

Perusahaan mulai efektif listing di bursa efek sejak 22 Agustus 1989. Pada tahun 2007 perusahaan mencatat laba bersih Rp 83,6 milyar. 
o. PT Modernland Realty Tbk.

Perusahaan didirikan pada 8 Agustus 1983 bergerak di bidang pengembang real estate, penyewaan properti dan pengelolaan fasilitas rekreasi. Mulai eketif listing di bursa efek sejak 18 Desember 1992. Pada tahun 2007 perusahaan mencatat laba bersih $\mathrm{Rp} 30,3$ milyar.

p. PT Ciputra Development Tbk

Perusahaan didirikan pada 22 Desember 1994 bergerak di bidang pengembangan real estate, perkantoran, pusat rekreasi. Pada tahun 2007 perusahaan mencatat laba bersih Rp 168 milyar.

q. PT Duta Anggada Realty Tbk.

Perusahaan bergerak di bidang pengembangan real estate, perkantoran, pusat rekreasi. Mulai efektif listing di bursa efek sejak 10 Maret 1995. Pada tahun 2007 perusahaan mencatat laba bersih Rp 100 milyar.

\section{Instrumentasi dan Pengumpulan Data}

Data-data yang digunakan dalam penelitian ini berasal dari data sekunder, yang dikumpulkan melalui langkah-langkah berikut: (1) melakukan studi pustaka, yaitu mengumpulkan informasi mengenai teori struktur modal perusahaan, nilai perusahaan, tingkat pertumbuhan perusahaan, dan faktorfaktor yang mempengaruhinya, serta informasi-informasi lain yang berhubungan, dari buku-buku referensi, jurnal penelitian, artikel maupun literatur-literatur lainnya, (2) melakukan studi lapangan dan dokumentasi, yaitu mengumpulkan data-data perusahaan publik dalam sektor pertambangan yang menjadi emiten di Bursa Efek Indonesia, meliputi deskripsi obyek penelitian dan laporan keuangan obyek penelitian yang telah diaudit, untuk tahun $2003-2007$.

\section{Metode Analisis Data}

Langkah-langkah analisis yang akan dilakukan pada penelitian ini adalah sebagai berikut:

(1) Menguji karakteristik hubungan antar variabel bebas.
Pengujian atas beberapa persyaratan tersebut dinamakan sebagai uji asumsi klasik sebagai berikut :

a) Uji Normalitas

Uji normalitas ini bertujuan untuk menguji apakah dalam model regresi, variable terikat dan variable bebas keduanya mempunyai distribusi normal atau tidak. Model regresi yang baik adalah yang memiliki distribusi data normal atau mendekati normal. Uji normalitas yang dilakukan dalam penelitian ini yaitu dengan mengunakan analisis grafik, yaitu dengan melihat histogram yang membandingkan antara data observasi dengan distribusi yang mendekati distribusi normal. Dasar pengambilan keputusan: Jika data yang menyebar di sekitar garis diagonal dan mengikuti arah garis diagonal, maka model ini memenuhi asumsi normalitas. Jika data menyebar jauh dari garis diagonal dan tidak mengikuti arah garis diagonal, maka model ini tidak memenuhi asumsi normalitas.

Pengujian penggunaan multiple linear regression diadakan dengan melakukan:

a) Uji Heterokedastisitas

Uji heterokedastisitas ini bertujuan untuk menguji apakah dalam model regresi terjadi ketidaksamaan varians dari residual satu pengamatan ke pengamatan yang lain. Jika variance dari residual satu pengamatan ke pengamatan yang lain tetap, maka diseburt homokedastiditas dan jika berbeda maka disebut heterokedastitas.

Uji heterokedastisitas yang dilakukan dalam penelitian ini yaitu dengan uji Glejser. Dimana dalam uji ini kita harus mengabsolutkan nilai residual dan kemudian meregresikan nilai absolute residual dengan variablevariabel bebas. Jika probabilitas signifikan dari masing-masing variable bebas memiliki tingkat kepercayaan $5 \%$ maka dapat disimpulkan adanya heterokedastisitas. 


\section{b) Uji autokorelasi}

Uji korelasi ini dilakukan untuk menguji apakah dalam suatu model regresi linear ada korelasi. Jika terjadi korelasi maka terdapat autokorelasi. Pada umumnya masalah autokorelasi ini sering ditemukan pada data time series (runtut waktu), sedangkan untuk data crossection (silang waktu), masalah autokorelasi relatif jarang terjadi. Tetapi apakah di dalam penelitian ini terdapat masalah autokorelasi, maka akan menguji autokorelasi ini dengan menggunakan uji Durbin-Watson.

Berikut adalah langkah-langkah analisisnya: (1) menentukan hipotesis. H0: Tidak ada autokorelasi, H1: Ada autokorelasi. (2) menentukan tingkat kepercayaan yaitu sebesar 5\% (3) Cari nilai $\mathrm{d}_{\mathrm{L}}$ dan $\mathrm{d}_{\mathrm{U}}$ dari table kritis Durbin - Watson sesuai dengan banyaknya sample (n) dan banyaknya variable bebas (k). (4) Hitung nilai (4-dU) dan (4-dL). (5) Bandingkan nilai Durbin Watson (d) dengan kritis Durbin Watson.

Pengambilan keputusan ada tidaknya autokorelasi: (1) Bila nilai DW terletak antara batas atas atau upper bound (du) dan (4-dU), maka koefisien autokorelasi sama dengan nol, berarti tidak ada autokorelasi. (2) Bila nilai DW lebih rendah daripada batas bawah atau lower bound (dl), maka koefisien autokorelasi lebih besar daripada nol, berarti ada ada autokorelasi positif. (3) bila nilai DW lebih besar daripada (4-dl), maka koefisien autokorelasi lebih kecil daripada nol, berarti ada autokorelasi negatif. (4) bilai nilai DW terletak di antara batas atas (du) dan batas bawah (dl) atau DW terletak antara (4-dU) dan (4-dL), maka hasilnya tidak dapat disimpulkan.

c) Uji Multikolinieritas

Uji Multikolinearitas ini digunakan untuk mengetahui apakah dalam model regresi ditemukan adanya korelasi antar variable-variabel bebas. Jika terjadi korelasi, maka terdapat multikolinearitas. Model regresi yang baik seharusnya tidak terjadi korelasi diantara variable-variabel bebas. Untuk mendeteksi ada atau tidaknya multikolinieritas didalam model regresi adalah sebagai berikut: Nilai VIF (Variance Inflation Factor) kurang dari 10 , atau nilai tolerance lebih besar 0.1 (Tolerance $=1 / \mathrm{VIF}$ atau $\mathrm{VIF}=1 /$ Tolarance).

(2) Melakukan analisis regresi melalui persamaan multiple linear regression.

Untuk menguji hipotesis tentang kekuatan variabel bebas terhadap struktur modal (capital structure), dalam penelitian ini digunakan analisis data secara statistic dengan menggunakan metode multiple liniear regression yang dilakukan sesuai hipotesis penelitian. Adapun model penelitiannya adalah sebagai berikut:

$\mathrm{CS}=\alpha+\beta 1(\mathrm{CB})+\beta 2(\mathrm{PR})+\beta 3(\mathrm{CVA})$ Dimana :

$$
\begin{aligned}
& \alpha=\text { Konstanta } \\
& \beta 1, \beta 2, \beta 3= \text { Koefisien Regresi } \\
& \mathrm{CB}=\text { Biaya bunga pinjaman (cost of } \\
& \text { borrowing) } \\
& \mathrm{PR}=\begin{array}{c}
\text { Tingkat } \\
\text { (profitability) }
\end{array} \\
& \mathrm{CVA}= \text { Nilai jaminan assets } \\
& \mathrm{CS}= \text { (collateral value of asets) } \\
& \text { Sruktur modal (capital } \\
& \text { structure) }
\end{aligned}
$$

(3) Melakukan analisis korelasi dengan menggunakan model Pearson correlation. Ukuran koefisien korelasi berkisar antara 1 sampai dengan +1. Semakin dekat dengan -1 berarti hubungan antara variabel-variabel tersebut negatif dan kuat. Semakin dekat dengan +1 berarti hubungan antara variabel-variabel tersebut positif dan kuat. Sedangkan semakin dekat dengan 0 berarti variabel-variabel tersebut semakin tidak berhubungan.

(4) Melakukan uji signifikansi untuk mengetahui variabel-variabel bebas yang 
Ade Suryana, Pengaruh Cost Of Borrowing, Profitability Dan Collateral Value Of Assets...

memiliki pengaruh signifikan terhadap variabel terikat. Uji signifikansi terdiri dari uji $\mathrm{t}(t$ test $)$ dan uji $\mathrm{F}(F$ test).

Koefisien regresi Simultan (Uji Statistik F) digunakan untuk menunjukkan apakah semua variable bebas yang dimasukkan dalam model mempunyai pengaruh secara bersama-sama terhadap variable terikat. Dengan kata lain uji $\mathrm{F}$ digunakan utnuk melihat apakah model yang digunakan tersebut signifikan atau tidak signifikan untuk digunakan dalam penelitian. Hasil hitung $\mathrm{F}$ nantinya akan dibandingkan dengan nilai $\mathrm{F}$ table dari table statistic berdasarkan jumlah sample yang digunakan.

Ho tidak dapat ditolak jika $\mathrm{F}$ hitung $\leq \mathrm{F}$ table, yang berarti tidak ada hubungan antara variable bebas secara bersamasama dengan variable terikat, sebaliknya Ha diterima jika $F$ hitung $>F$ table yang berarti ada hubungan signifikan antara variable bebas secara bersama-sama dengan variable terikat.
(5) Hasil pengujian tersebut dianalisis untuk kemudian ditarik kesimpulan mengenai bagaimana hubungan antara tingkat leverage, rasio pengeluaran modal dan marjin keuntungan dengan nilai perusahaan dengan memperhitungkan adanya kesempatan pertumbuhan yang berbeda pada masing-masing perusahaan. Kesimpulan tersebut dilanjutkan dengan memberikan saran serta implikasi manajemen terkait.

Analisis data secara statistik dengan menggunakan metode multiple linear regression ini dilakukan dengan bantuan program Statistical Packages for Social Sciences/Personal Computer (SPSS/PC).

\section{PEMBAHASAN HASIL PENELITIAN}

\section{Statistik Deskriptif}

Deskripsi statistik dari variabel-variabel dalam penelitian ini dapat dilihat pada tabel 3 berikut:

Tabel 3

Deskripsi Statistik Variabel

(dalam persen - kecuali standar deviasi)

\begin{tabular}{|l|c|r|r|r|r|}
\hline \multicolumn{1}{|c|}{ Variabel } & N & Minimum & \multicolumn{1}{c|}{ Maksimum } & \multicolumn{1}{c|}{ Mean } & \multicolumn{1}{c|}{$\begin{array}{c}\text { Standar } \\
\text { Deviasi }\end{array}$} \\
\hline Capital Structure (CS) & 85 & 0,0076 & 6,9988 & 1,0529 & 1,2296 \\
\hline Cost of Borrowing (CB) & 85 & 0,0002 & 0,4189 & 0,0952 & 0,0857 \\
\hline Profitability (PR) & 85 & $-0,0330$ & 0,1579 & 0,0337 & 0,0424 \\
\hline $\begin{array}{l}\text { Collateral Value of Assets } \\
\text { (CVA) }\end{array}$ & 85 & 0,0752 & 0,8339 & 0,4620 & 0,1996 \\
\hline
\end{tabular}

Sumber: Lampiran 2 - Data Keuangan Emiten Real Estate Bursa Efek Jakarta

Tahun 2003 - 2007

Berdasarkan perhitungan, rata-rata (mean) variabel capital structure adalah 1,0529 dengan standar deviasi 1,2296. Capital structure dihitung sebagai rasio antara jumlah pinjaman perusahaan pada akhir tahun buku dengan nilai ekuitas pada tanggal tersebut. Rata-rata capital structure yang relatif kecil disebabkan karena kebanyakan perusahaan real estate memiliki jumlah pinjaman yang relatif kecil dengan range cukup lebar, yaitu antara $\mathrm{Rp} 466,4$ juta (jumlah pinjaman PT Roda Panggon Harapan Tbk tahun 2006) dan Rp 3,0 trilyun (jumlah pinjaman PT Duta Pertiwi Tbk tahun 2003), namun memiliki nilai ekuitas yang relatif tinggi

Selanjutnya, rata-rata cost of borrowing adalah 0,0952 dengan standar deviasi 0,0857. Cost of borrowing dihitung sebagai rasio antara beban bunga pinjaman selama tahun buku dengan jumlah pinjaman pada akhir tahun buku yang sama

Rata-rata Profitability adalah 0,0337 dengan standar deviasi 0,0424. Profitability dihitung sebagai rasio antara laba operasi selama suatu periode pelaporan dengan total assets perusahaan pada akhir periode pelaporan yang sama. 
Terakhir, rata-rata collateral value of assets adalah 0,4620 dengan standar deviasi 0,1996. Collateral value of assets dihitung sebagai rasio antara piutang, persediaan dan aktiva bersih pada akhir periode pelaporan dengan total asset pada akhir periode yang sama.

\section{Uji Asumsi Klasik}

\section{a. Uji Multikolinearitas}

Hasil uji multikolinearitas dapat dilihat pada tabel 4 berikut:

Tabel 4

Hasil Uji Multikolinearitas

\begin{tabular}{|l|r|r|r|r|r|}
\hline \multirow{2}{*}{ Variabel } & \multicolumn{3}{|c|}{ Korelasi } & \multicolumn{2}{c|}{ Collinearity Statistics } \\
\cline { 2 - 6 } & CB & \multicolumn{1}{c|}{ PR } & CVA & Tolerance & \multicolumn{1}{c|}{ VIF } \\
\hline CB & 1,000 & 0,119 & 0,130 & 0,975 & 1,026 \\
\hline PR & 0,119 & 1,000 & 0,248 & 0,931 & 1,074 \\
\hline CVA & 0,130 & 0,248 & 1,000 & 0,928 & 1,077 \\
\hline
\end{tabular}

Dari tabel di atas dapat diketahui besaran korelasi antar variabel bebas untuk mengetahui apakah terdapat multikolinearitas antar variabel bebas. Jika tingkat korelasi masih berada di bawah 0,9 (90\%), dapat dikatakan bahwa tidak terjadi kolinearitas yang serius. Nilai besaran korelasi yang diperoleh dari perhitungan di atas seluruhnya berada di bawah 0,9 (90\%), yaitu 24,8,0\%, $13,0 \%$, dan $11,9 \%$. Hasil perhitungan nilai tolerance juga menunjukkan tidak ada variabel bebas yang memiliki nilai kurang dari 0,1 (10\%), berarti tidak ada korelasi antar variabel bebas. Begitu pula dengan hasil perhitungan variance inflation factor (VIF), seluruh hasil perhitungan VIF memiliki nilai lebih kecil dari 10 (yaitu 1,077, 1,074, dan 1,026). Dengan demikian dapat disimpulkan bahwa tidak terdapat multikolinearitas antara variabel bebas.

\section{b. Uji Autokorelasi}

Hasil uji autokorelasi Durbin-Watson (DW) adalah seperti terlihat pada tabel 5 berikut:

Tabel 5

Hasil Uji Autokorelasi

\begin{tabular}{|c|c|c|c|c|}
\hline$R$ & $R$ Square & Adjusted $R$ Square & $\begin{array}{c}\text { Std. Error of the } \\
\text { Estimate }\end{array}$ & Durbin-Watson \\
\hline 0,312 & 0,098 & 0,064 & 1,1895 & 2,048 \\
\hline
\end{tabular}

Nilai DW yang diperoleh dari uji autokorelasi adalah 2,048. Berdasarkan table DurbinWatson Statistic Significance Points for TwoTailed Test, untuk jumlah sampel $(\mathrm{n})=85$ dengan jumlah variabel bebas $(\mathrm{k})=3$ variabel diperoleh data sebagai berikut batas bawah (dl) 1,575 dan batas atas (du) 1,721. Sehingga dapat diketahui nilai 4-dl adalah 2,425 dan 4du adalah 2,279.

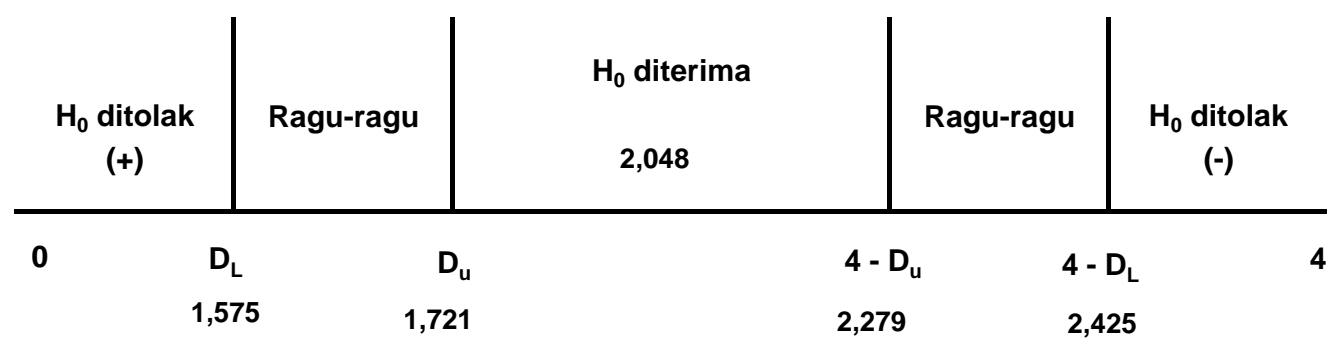

Nilai DW hasil perhitungan terletal di antara du dan 4-du. Sehingga dapat disimpulkan bahwa tidak terdapat autokorelasi dalam model penelitian. 
Ade Suryana, Pengaruh Cost Of Borrowing, Profitability Dan Collateral Value Of Assets...

\section{c. Uji Heterokedastisitas}

Uji heterokedastisitas ini dilakukan dengan mengamati grafik scatterplot dari perhitungan statistik atas data-data penelitian ini. Dari grafik scatterplot pada gambar 2 di bawah ini terlihat bahwa titik-titik tidak membentuk pola yang jelas, dan menyebar di atas dan di bawah angka 0 pada sumbu Y, sehingga dapat disimpulkan bahwa tidak terjadi heterokedastisitas pada variabel bebas.

Gambar 2.

Uji Heterokedastisitas - Grafik Scatterplot

Scatterplot

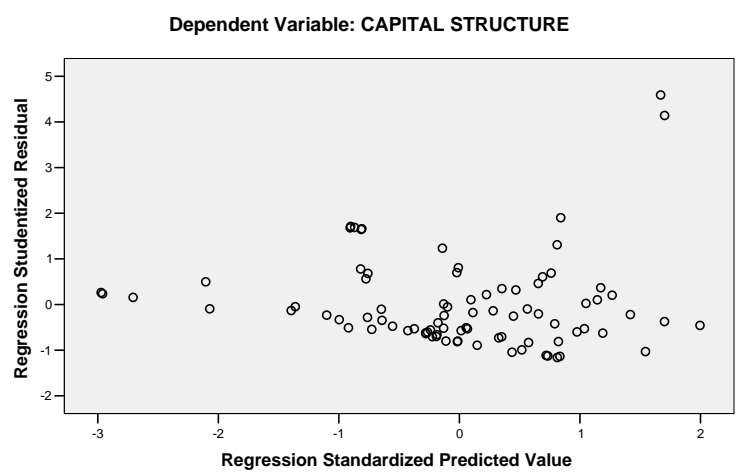

\section{d. Uji Normalitas}

Hasil uji normalitas dapat dilihat dari grafik normal plot probability pada gambar 3 berikut, di mana terdapat titik-titik yang menyebar di sekitar garis diagonal, serta penyebarannya mengikuti arah garis diagonal, sehingga membentuk suatu kurva yang mendekat garis diagonal distribusi normal. Hal ini menunjukkan model regresi layak dipakai karena memenuhi asumsi normalitas.

Gambar 3

Uji Normalitas - Grafik Normal Probability Plot

Normal P-P Plot of Regression Standardized Residual

Dependent Variable: CAPITAL STRUCTURE

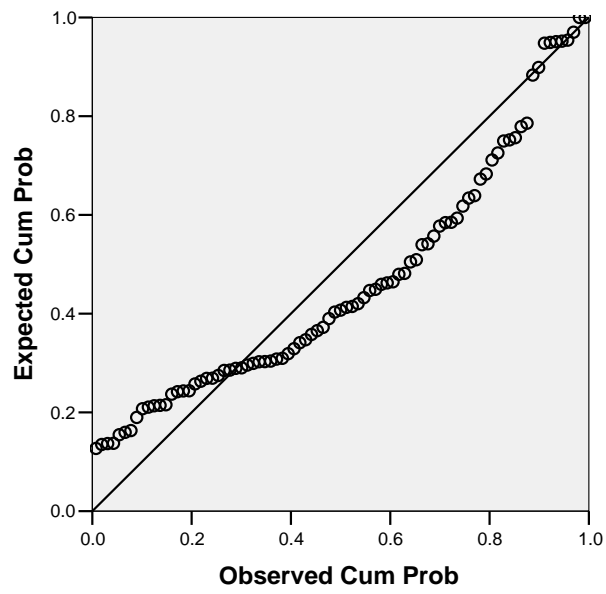


Majalah Ilmiah Institut STIAMI

ISSN 1411-0830

\section{Analisis Hasil dan Interpretasi}

a. Analisis Model Regresi
Analisis model regresi dilakukan dengan melihat nilai konstanta (intercept) dan koefisien regresi (slope of regression) variabel-variabel bebas.

Tabel 6

Koefisien Variabel Bebas

\begin{tabular}{|c|c|c|c|c|c|}
\hline & \multicolumn{2}{|c|}{ Unstandardized Coefficients } & $\begin{array}{c}\text { Standardized } \\
\text { Coefficients }\end{array}$ & \multirow{2}{*}{$T$} & \multirow{2}{*}{ Sig. } \\
\cline { 2 - 4 } & $B$ & Std. Error & Beta & & \\
\hline (Constant) & 0,938 & 0,344 & & 2,726 & 0,008 \\
\hline CB & $-4,001$ & 1,533 & $-0,279$ & $-2,610$ & 0,011 \\
\hline PR & 2,921 & 3,173 & 0,101 & 0,921 & 0,360 \\
\hline CVA & 0,859 & 0,675 & 0,139 & 1,272 & 0,207 \\
\hline
\end{tabular}

Berdasarkan data-data pada tabel di atas, maka diperoleh persamaan regresi sebagai berikut:

$\mathrm{CS}=0,398-4,001 \mathrm{CB}+2,921 \mathrm{PR}+0,859$ CVA

Dimana:

$\begin{array}{ll}\mathrm{CS} & =\text { corporate structure } \\ 0,938 & =\text { intercept } \\ -4,001 & =\text { slope coefficient } \mathrm{CB} \\ \mathrm{CB} & =\text { cost of borrowing } \\ 2,921 & =\text { slope coefficient } P R \\ \mathrm{PR} & =\text { profitability } \\ 0,859 & =\text { slope coefficient } \mathrm{CVA} \\ \mathrm{CVA} & =\text { collateral value of assets }\end{array}$

Dalam melakukan perhitungan regresi di atas, tidak ada variabel yang dikeluarkan (removed), atau dengan kata lain seluruh variabel bebas dimasukkan dalam perhitungan regresi.

Intercept sebesar 0,938 berarti bahwa jika tidak ada ketiga variabel bebas di atas, atau jika nilai ketiga variabel bebas tersebut sama dengan nol, maka capital structure yang diperoleh, yang merupakan rasio antara jumlah pinjaman dengan nilai ekuitas, adalah sebesar 0,938. Atau dengan kata lain jumlah pinjaman adalah 0,938 dari nilai ekuitas.

Koefisien regresi CB sebesar - 4,001 berarti bahwa setiap penambahan cost of borrowing ratio sebesar 1, akan menurunkan nilai capital structure sebesar $40,01 \%$. Koefisien regresi PR sebesar 2,921 berarti bahwa setiap penambahan profitability ratio sebesar 1, akan meningkatkan nilai capital structure sebesar $29,21 \%$. Koefisien regresi CVA sebesar 0,859 berarti bahwa setiap penambahan collateral value of assets ratio sebesar 1, akan meningkatkan capital structure sebesar $8,59 \%$.

\section{b. Analisis Korelasi}

Seperti terlihat pada tabel 4.3 di atas, nilai $R$-square yang diperoleh adalah 0,098 dimana lebih kecil dari nilai $\mathrm{R}$ yaitu 0,606 .. Hal ini berarti capital structure dengan cost of borrowing, profitability dan collateral value of assets memiliki hubungan positif namun tidak kuat. Selanjutnya, nilai adjusted $R$ square sebesar 0,064 berarti bahwa hanya $6,40 \%$ capital structure dapat dijelaskan oleh variabel cost of borrowing ratio, profitability ratio dan collateral value of assets ratio, sisanya sebesar 93,60\% disebabkan oleh halhal lain. Beberapa faktor di antara hal-hal lain yang bisa menjelaskan capital structure adalah cost of equity, size of the firm, growth rate, liquidity ratio, non-debt tax shields, debt-to-asset structure, dan pre-tax profit margin, seperti telah diuraikan secara singkat pada bab-bab awal penelitian ini.

Standard error of estimate pada regresi linear berganda ini adalah sebesar 1,1895, dengan satuan yang dipakai adalah capital structure sebagai variabel terikat. Nilai tersebut lebih kecil daripada standar deviasi nilai perusahaan pada tabel 4.1, yaitu 1,2296, sehingga model regresi lebih bagus dalam bertindak sebagai prediktor nilai perusahaan 
Ade Suryana, Pengaruh Cost Of Borrowing, Profitability Dan Collateral Value Of Assets...

dibandingkan dengan rata-rata nilai perusahaan itu sendiri.

Hasil uji $\mathrm{F}$ dapat dilihat pada tabel 7 berikut ini:

\section{c. Hasil Uji F}

Tabel 7

Hasil Uji F

\begin{tabular}{|l|r|r|r|r|r|}
\hline & \multicolumn{1}{|c|}{$\begin{array}{c}\text { Sum of } \\
\text { Squares }\end{array}$} & Df & $\begin{array}{c}\text { Mean } \\
\text { Square }\end{array}$ & F & Sig. \\
\hline Regression & 12,390 & 3 & 4,130 & 2,919 & 0,039 \\
Residual & 114,614 & 81 & 1,415 & & \\
Total & 127,003 & 84 & & & \\
\hline
\end{tabular}

Dari uji $\mathrm{F}$ tersebut, didapatkan nilai $\mathrm{F}$ hitung adalah 2,919 dengan tingkat signifikansi 0,039. Karena probabilitas tersebut $(0,039)$ lebih kecil dari 0,05 , maka model regresi dapat dipakai untuk memprediksi nilai perusahaan. Atau dengan kata lain, cost of borrowing, profitability dan collateral value of assets secara bersamasama berpengaruh secara signifikan terhadap nilai perusahaan.

Terkait dengan adanya pengaruh ketiga variabel tersebut secara bersama-sama, dari standard coefficient beta pada tabel 4.4, terlihat bahwa tingkat collateral value of assets memiliki koefisien yang terbesar, yaitu
0,139, sementara profitability memiliki koefisien sebesar 0,101 sedangkan cost of borrowing ratio memiliki koefisien negatif. Hal ini menandakan bahwa tingkat collateral value of assets merupakan faktor yang lebih dominan dalam penentuan struktur modal (capital structure) dibandingkan dengan profitability.

\section{d. Hasil uji parsial}

Pengujian digunakan untuk mengetahui pengaruh dari masing-masing variable independen terhadap variable dependen.

Tabel 8

Hasil Analisis Uji-t

\begin{tabular}{|c|c|c|c|c|c|c|c|c|c|c|c|}
\hline \multicolumn{12}{|c|}{ Cosmolsnts" } \\
\hline \multirow[b]{2}{*}{ Model } & & \multicolumn{2}{|c|}{$\begin{array}{l}\text { Urstanderdized } \\
\text { Coemliglens }\end{array}$} & \multirow{2}{*}{$\begin{array}{l}\text { Standerd ined } \\
\text { Coemilelenss } \\
\text { Bess }\end{array}$} & \multirow[b]{2}{*}{ : } & \multirow[b]{2}{*}{$\mathrm{Sg}$. } & \multicolumn{3}{|c|}{ Comelg:ions } & \multicolumn{2}{|c|}{ Collinearity Gas:s:ics } \\
\hline & & B & Sod. Emor & & & & Zero-order & Partigl & Par: & Tolerance & VF \\
\hline \multirow[t]{4}{*}{1} & (Constant) & 938 & 344 & & 2,725 & .008 & & & & & \\
\hline & COST OF BORAOWNGS & -4.001 & 1,533 & -.279 & -2.610 & .011 & -249 & -278 & -.275 & 975 & 1,025 \\
\hline & PRORITABIUITY & 2.921 & 3,173 & .101 & 921 & 390 & .102 & .102 & .097 & 931 & 1,074 \\
\hline & $\begin{array}{l}\text { COLLATERAL VALUE OF } \\
\text { ASSETS }\end{array}$ & .859 & .675 & .139 & 1,272 & .207 & .128 & .140 & .134 & .928 & 1,077 \\
\hline
\end{tabular}

Dari hasil analisis uji-t tabel 8 di atas, maka dapat dijelaskan sebagai berikut :

\section{Hipotesis Pertama}

Koefisien regresi tingkat cost of borrowing (CB) sebesar $-4,001$ berarti bahwa setiap penambahan tingkat cost of borrowing sebesar 1, akan menurunkan struktur modal perusahaan sebesar $400,10 \%$. Sementara, probabilitas signifikansi variabel tingkat cost of borrowing adalah sebesar 0,011, dimana pada tingkat keyakinan 5\% nilai tersebut lebih kecil dari 0,05, sehingga dapat diartikan bahwa variabel tingkat cost of borrowing memiliki pengaruh negatif yang signifikan terhadap nilai perusahaan. Dengan kata lain, $\mathrm{H}_{0} 1$ ditolak.

Kesimpulan uji hipotesis pertama ini juga sejalan dengan hasil penelitian sebelumnya oleh Bhole dan Mahakud (2004) yang keduanya sama-sama membuktikan adanya korelasi negatif antara cost of borrowing dengan struktur modal perusahaan.

\section{Hipotesis Kedua}


Koefisien regresi rasio profitability (PR) sebesar 2,921 berarti bahwa setiap penambahan profitability sebesar 1, akan meningkatkan struktur modal perusahaan sebesar 292,10\%. Sementara, probabilitas signifikansi variabel rasio pengeluaran modal adalah sebesar 0,360, dimana nilai tersebut lebih besar dari 0,05, sehingga dapat diartikan bahwa variabel rasio profitability memiliki pengaruh positif namun tidak signifikan terhadap struktur modal perusahaan. Dengan kata lain $\mathrm{H}_{0} 2$ gagal ditolak.

Kesimpulan ini sejalan dengan penelitian Chen dan Zhao, 2004, dimana semakin menguntungkan perusahaan akan memiliki rasio leverage yang lebih tinggi, cateris paribus ketika keuntungan pajak, biaya kebangkrutan dan masalah arus kas dipertimbangkan.

\section{Hipotesis Ketiga}

Koefisien regresi collateral value of assets (CVA) sebesar 0,859 berarti bahwa setiap penambahan collateral value of assets sebesar 1, akan meningkatkan nilai capital structure perusahaan sebesar 85,90\%. Sementara, probabilitas signifikansi variabel profit margin adalah sebesar 0,207, dimana pada tingkat keyakinan 5\% nilai tersebut lebih besar dari 0,05 , sehingga dapat diartikan bahwa variabel collateral value of assets tidak memiliki pengaruh signifikan terhadap nilai perusahaan. Dengan kata lain, $\mathrm{H}_{0} 3$ diterima.

Hasil perhitungan di atas menunjukkan bahwa collateral value of assets suatu perusahaan merupakan salah satu faktor yang dapat mempengaruhi struktur modal perusahaan tersebut.

\section{Hipotesis Keempat}

Dari hasil perhitungan, $R$-square yang diperoleh adalah 0,098, yang berarti antara struktur modal dengan cost of borrowing, profitability dan collateral value of assets memiliki hubungan positif walaupun tidak kuat. Sementara, nilai F hitung adalah 2,919 dengan tingkat signifikansi 0,039. Karena probabilitas tersebut $(0,039)$ lebih kecil dari
0,05, maka dapat disimpulkan bahwa secara bersama-sama tingkat cost of borrowing, profitability dan collateral value of assets berpengaruh signifikan pada struktur modal. Dengan kata lain, $\mathrm{H}_{0} 4$ diterima.

Hasil pengujian hipotesis keempat ini tentunya terkait dengan kesimpulan pengujian ketiga hipotesis sebelumnya dimana dapat dilihat bahwa secara individual, tingkat cost of borrowing memiliki pengaruh yang signifikan terhadap struktur modal, sementara rasio profitability dan collateral value of assets tidak memiliki pengaruh yang signifikan.

\section{KESIMPULAN}

1. Terdapat pengaruh negatif yang signifikan dari rasio cost of borrowing terhadap capital structure pada perusahaan real estate di Indonesia. Kesimpulan ini dapat dijelaskan karena perusahaan cenderung akan menghindari beban bunga yang tinggi. Sehingga akan memiliki kecenderungan tidak akan menggunakan pinjaman atau mengurangi pinjaman untuk investasinya pada saat beban pinjaman (bunga) cenderung tinggi.

2. Terdapat pengaruh positif meskipun tidak signifikan dari rasio profitability terhadap capital structure pada perusahaan real estate di Indonesia. Hal ini dapat dijelaskan karena tingginya rasio profitability akan memberikan peluang lebih banyak kepada perusahaan untuk mendapatkan pinjaman. Di sisi lain, tingginya rasio profitability juga tidak secara langsung dapat mempengaruhi capital structure, karena masih banyak faktor lain yang mempengaruhi hal tersebut.

3. Terdapat pengaruh positif namun tidak signifikan dari collateral value of assets terhadap capital structure pada perusahaan real estate di Indonesia. Hal ini sejalan dengan kenyataan bahwa nilai assets yang dijadikan sebagai jaminan yang dimiliki meskipun mejadi bahan pertimbangan 
Ade Suryana, Pengaruh Cost Of Borrowing, Profitability Dan Collateral Value Of Assets...

investor, namun tidak serta merta menjadi faktor utama untuk diperhatikan.

4. Terdapat pengaruh signifikan dari variabel tingkat cost of borrowing, profitability dan collateral value of assets secara bersama-sama terhadap struktur modal (capital structure) pada perusahaan real estate di Indonesia, yang secara jelas telah dibuktikan melalui hasil $\mathrm{F}$ hitung dan nilai $R$-square yang menjadi dasar kesimpulan tersebut (lihat Tabel 4.5). Namun jika ketiga variabel bebas tersebut berdiri sendiri, hanya variabel tingkat cost of borrowing yang secara mutlak memiliki pengaruh negatif dan signifikan terhadap struktur modal, sementara profitability dan collateral value of asset memiliki pengaruh positif namun tidak signifikan (lihat Tabel 4.4).

\section{Implikasi Manajerial}

Dari hasil penelitian di atas dapat diketahui bahwa variabel tingkat cost of borrowing merupakan faktor yang sangat menentukan struktur modal (capital structure). Semakin tinggi tingkat bunga atau beban pinjaman, akan menurunkan minat perusahaan untuk mendanai investasinya dengan pinjaman. Perusahaan akan cenderung menggunakan modal sendiri dan bagian laba ditahan untuk pendanaannya. Sedangkan profitability dan collateral value of assets memiliki pengaruh positif meskipun tidak signifikan. Tingginya tingkat profitabilitas (profitability) dan aktiva yang dijaminkan (collateral value of assets) akan menjadi bahan pertimbangan investor dalam memberikan pinjaman meskipun bukan faktor utama yang perlu dipertimbangkan. Dengan demikian, bagi perusahaan real estate yang memerlukan dana cukup besar untuk investasi dan pengembangan bisnisnya nya, harus mempertimbangkan tingginya tingkat suku bunga yang akan menjadi beban pinjamna. Pemilihan pinjaman dengan tingkat bunga yang optimal akan memberikan dampak positif untuk pertumbuhan perusahaan. Perusahaan juga disarankan mempertimbangkan tingginya tingkat profitability dan collateral value of assets. Hal ini untuk memberikan jaminan kepada investor akan kemampuan perusahaan dalam memenuhi kewajibannya.

\section{SARAN}

Untuk penelitian selanjutnya, disarankan agar pengujian dapat diarahkan kepada pengembangan model yang dinamis tetapi memungkinkan dilakukannya optimisasi terhadap variabel-variabel bebas yang berhubungan terhadap struktur modal. Seperti telah dibahas pada bab II penelitian ini, terdapat beberapa teori yang mengungkapkan adanya faktor-faktor lain yang dapat mempengaruhi struktur modal, seperti cost of equity, size of the firm, growth rate, liquidity, non-debt tax shields, dan pretax profit margin (Bhole dan Mahakud (2004)). Selain itu disarankan agar penelitian selanjutnya menggunakan pendekatan metode statistik yang berbeda yang dilandasi dengan pemahaman ilmu ekonomi yang lebih baik, dan dapat menggunakan asumsi-asumsi yang tidak digunakan dalam penelitian ini, misalnya memperhitungkan faktor financial distress, agency cost, kebijakan pemerintah, dan sebagainya, serta menambah variabel bebas yang digunakan. Penelitian selanjutnya juga dapat dilakukan pada sektor industri yang berbeda, dengan jumlah sampel yang mungkin lebih banyak dan periode penelitian yang lebih lama, sehingga kesimpulan penelitian lebih dapat diberlakukan secara umum.

\section{DAFTAR PUSTAKA}

Amir, Mohammad Faisal, 2006, "Mengolah dan Membuat Interpretasi Hasil Olahan SPSS untuk Penelitian Ilmiah”, Jakarta : EDSA Mahkota.

Arifin, Zaenal, 2006, “Teori Keuangan dan Pasar Modal”, Yogyakarta, Ekonesia.

Bhole, L.M. dan Mahakud Jitendra (2004), "Trends and Determinant of Corporate Structure in India: A Panel Data Analysis".Journal of Finance, Vol. XVIII No. 1, March. 
ISSN 1411-0830

Booth, L., V. Aivazian, A. Dermigue-Kunt, and Maksimovic, (2000), "Capital Structure in Developing Countries", Journal of Finance.

Brealey, Richard A., Stewart C. Myers, (2003), "Principles of Corporate Finance", $7^{\text {th }}$ edition, New York : McGraw-Hill Companies Inc.

Chen, Kaifeng, (2002), "The Influence of Capital Structure on Company Value with Different Growth Opportunities", FAME and University of Lausanne.

Damodaran, Aswath, (2001), "Corporate Finance, Theory and Practice", $2^{\text {nd }}$ edition, New Jersey : John Wiley \& Sons, Inc.

Ghozali, Imam, (2005), "Aplikasi Analisis Multivariate dengan Program SPSS”, edisi 3, Semarang, Badan Penerbit Undip.

Gujarati, Damodar N., (2003) "Basic Econometrics", $4^{\text {th }}$ edition, New York: McGraw-Hill/Irwin.

Haspeslag, P.C., and Jernison, D.B. (1991). "Managing acquisitions: Creating value through corporate renewa", New York: The Free Press.
Keown, Arthur J., John D. Martin, J. William Petty dan David F. Scott, Jr., "Financial Management:Principles and Applications", $10^{\text {th }}$ edition, New Jersey : Pearson Prentice Hall, 2005.

Riyanto, Bambang, (2001), "Dasar-dasar Pembelanjaan Perusahaan”, Edisi 4, Yogyakarta, BPFE.

Sartono, Agus, (2001), "Manajemen Keuangan: Teori dan Aplikasi”, Edisi 4, Yogyakarta, BPFE.

Sudarmanto, R. Gunawan, (2005), "Analisis Regresi Linear Ganda dengan SPSS", Yogyakarta: Penerbit Graha Ilmu.

Supranto, J., (1990), "Statistik - Teori dan Aplikasi Jilid 1 dan 2", Edisi Kelima, Jakarta: Penerbit Erlangga.

Van Horne, James C., (1998), "Financial Management and Policy", $11^{\text {th }}$ edition, New Jersey : Prentice-Hall Inc.

Wahyono, Teguh, (2006), "Analisis Data Statistik dengan SPSS 14", Jakarta : PT Elex Media Komputindo. 